\title{
Tendinitis crónica versus tendinosis en patología podológica. Marco citológico e histológico actual
}

\author{
Chronic tendinitis versus tendinosis in podiatric pathology. \\ Cytological and histological update
}

\author{
David Rodríguez Sanz ${ }^{(1,2)}$ \\ José David Cerdeño Arconada ${ }^{(1)}$
}

(1) Diplomado en Fisioterapia

(2) Diplomado en Podologia

\author{
Correspondencia: \\ David Rodríguez Sanz \\ S. M. Club Atlético de Madrid \\ Ciudad Deportiva Atlético de Madrid \\ $\mathrm{C} /$ Avda de Guadarrama s/n \\ 28220 Majadahonda \\ Madrid
}

Fecha de recepción: 10 agostp 2009

Fecha de aceptación: 2 noviembre 2009

Los autores declaran no tener ningún tipo de interés económico o comercial.

\section{RESUMEN}

Gran parte de las lesiones que se depositan en nuestro pie se encuentran en la estructura tendinosa por lo que consideramos de interés actualizar los conocimientos sobre esta y sus tejidos. A continuación realizaremos un trabajo de revisión con el fin de actualizar conceptos sobre las lesiones tendinosas que nos podrán ayudar a conocer y mejorar el diagnostico etiológico así como la actividad terapéutica que desarrollamos en nuestra actividad clínica.

Palabras clave: Histología, Tendón, Lesiones.

\begin{abstract}
Largely about injuries that appears in our feet, we can find into the tendinous structure, so its really necessary to refresh the knowledge about tendon structure an tissues. Below, we'll do a review so we can get the new ideas about injuries tendon so it helps us to improve our aetiology diagnosis and treatments that we do in our clinical activity.
\end{abstract}

Keywords: Histology, Tendon, injuries.

Sumario: 1. Introducción. 2. Epidemiología de las lesiones tendinosas. 3. Anatomohistología del tendón. 4. Inervación del tendón. 5. Vascularización del tendón. 5.1. Unión Miotendinosa. 5.2. Unión Osteotendinosa. 6. Comportamiento mecánico del tendón. 7. Actualización en tendinopatias. 8. Bibliografia.

\section{Referencia normalizada:}

Rodríguez Sanz D, Cerdeño Arconada JD. Tendinitis crónica versus tendinosis en patología podológica. Marco citológico e histórico actual. Revista Internacional de Ciencias Podológicas 2011; 5 (1): 37-43. 


\section{INTRODUCCIÓN}

De color blanco nacarado y consistencia fuerte, el tendón forma parte del conjunto muscular, en su mayor parte esta constituido por fibras de tejido conectivo que se agrupan en fascículos. El tendón representa de este modo un elemento de transmisión de las fuerzas mecánicas del músculo hacia el hueso. Así pues el tendón, podemos observar, se trata de una estructura compleja, tanto desde el punto de vista anatómico como mecánico.

Con el avance producido en la captura de imágenes titulares, así como el mejor análisis y conocimiento histológico, con entre otras RMN HD y análisis de microdialisis en vivo, nos aproximamos cada vez mas, a un conocimiento profundo acerca de las diferentes estructuras anatómicas que componen el cuerpo humano. El fin de este artículo es acercarnos a un conocimiento mas actualizado y completo del tendón centrándonos en su estructura, para mejorar nuestros procesos diagnósticos y optimizar nuestras técnicas de tratamiento.

\section{EPIDEMIOLOGÍA DE LAS LESIONES TENDINOSAS}

A continuación vamos a acercarnos a la importancia estadística de las lesiones tendinosas, con dos estimaciones epidemiológicas que pueden resultarnos significativas:

Las tendinosis, entendidas como aquel proceso degenerativo que se deposita en el tendón, puede encontrarse en aproximadamente un $48 \%$ de las enfermedades laborales informadas.

A nivel deportivo, con gran importancia encontramos las lesiones por sobreuso (overuse injuries) que afectan a tendón se aproximan a un $50 \%$ de las lesiones encontradas, siendo los tendones mas dañados el tendón rotuliano y el aquileo. Estas lesiones, se encuentran frecuentemente asociadas a alteraciones previas de carácter biomecánico.

\section{ANATOMOHISTOLOGÍA DEL TENDÓN}

En el tendón encontramos una gran matriz extracelular y un pequeño componente celular. En el pequeño componente celular encon- tramos de manera más llamativa tenocitos, tenoblastos, macrófagos, miofibroblastos, condrocitos, células sinoviales, células capilares endoteliales ${ }^{(1)}$.

Respecto a la matriz extracelular encontramos sustancia fundamental, tejido conjuntivo, colágeno, elastina y tenascina $\mathrm{C}$ principalmente.

Volviendo al componente celular, encontraremos a los tenoblastos donde cabe decir que son ricos en organelos y responsables en gran parte de síntesis y transporte proteico y ayudan a sintetizar los componentes extracelulares.

Según los estudios de Khan et al. Su presencia en tendón es escasa en proporción al numero de elementos de matriz extracelular, estos poseen un metabolismo bajo con un cociente respiratorio bajo y no tienen regulación central, estas estructuras responden a los estímulos locales que reciben en primera persona modificando así su forma, función y composición. Los tenoblastos poseen tres vías para obtener energía, a saber, ciclo de krebs, glucólisis anaerobia y la ruta de las pentosas fosfato. Estas tres vías permanecen activas mientras en tendón se desarrolla. Con el incremento de la edad solo la glicólisis permanece constante y la vía de las pentosa fosfato y el ciclo de krebs disminuye en actividad disminuyendo su aporte energético. Esto nos hace ver que existe un movimiento de vías aeróbicas a vías mas anaeróbicas asociado al transito en el tiempo y que esta vinculado a las modificaciones que acontecen en el tendón con la edad ${ }^{(2,3)}$.

Respecto a la Matriz extracelular, hablaremos sobre sus principales protagonistas, el colágeno y la sustancia fundamental:

El colágeno constituye aproximadamente el $90 \%$ del total de proteínas del tendón y proporciona resistencia frente a las fuerzas de tensión. La mayor parte encontrada es colágeno tipo I encontrando colágeno tipo III en el endotendon del tendón sano. Representa el 30\% del peso en el tendón fresco y el $80 \%$ del peso en seco. El colágeno además posee una característica geométrica, de elevado interés biomecánico, en la que sus fibras siguen las líneas de fuerza con un componente espiral, salvo que el tendón reciba fuerzas en todas los vectores del espacio, en este caso el tendón demostrará espirales en todos los vectores a los que se vea 
sometido. En el tendón normal, la estructura es jerárquica, dividiéndose claramente y con un perfil telescopico en 5 niveles diferentes, desde el nivel microscópico hasta el macroscópico ${ }^{3}$.

Es importante conocer que en el colágeno existen 2 tipos de enlaces cruzados, intramoleculares $(\alpha-1$ y $\alpha-2)$ e intermoleculares (subfibrillas, fibrillas y fibras colágenas) que le confieren resitencia frente a los elementos externos.

Respecto al metabolismo del tendón, cabe destacar que el colágeno esta en continua destrucción y formación debido a su carácter mecánico y es de nuestro interés saber que durante la etapa de crecimiento o tras un periodo lesional focalizado los fibroblastos centrar su actividad en la síntesis de tropocolageno. Tras un proceso lesivo depositado en tendón, la formación de colágeno alcanza un pico, posteriormente entre el día 14 y el día 28 , este proceso es de aproximadamente unas 22 veces mayor que en condiciones básales.

La sustancia fundamental organiza el tejido conjuntivo, estructurando y dando orientación a las fibras colágenas además garantizando la separación necesaria entre ellas. El agua constituye su principal componente, encontrando valores entre el $60 \%-80 \%$ del peso de la sustancia fundamental y permite la comunicación celular además de la difusión de nutrientes a través de la misma. Se encuentra formada por asociaciones de glucosaminoglicanos y glucoproteinas estructurales. Dentro de los glucosa- minoglicanos destacaremos el papel del acido hialurónico: Poseen una capacidad enorme para fijar agua (pudiendo absorber un volumen hidrodinámico equivalente a 1000 veces el espacio ocupado por la cadena en estado de deshidratación. Esto es de elevado interés dado que el acido hialurónico así como el agua procedente de la absorción son el principal lubricante entre fibras y fibrillas colágenas.

La principal glucoproteina estructural es la fibronectina de alto peso molecular, la cual juega un importante papel en la adhesión celular (célula-célula y célula-substrato) y en la migración celular.

Es fundamental reconocer que la resistencia del tejido de reparación tras una lesión la aportan las uniones de fibronectina y colágeno. La fibronectina actúa como un soporte para la formación de fibras colágenas durante la fase de remodelación.

Otras proteínas de gran importancia son las integrinas, destacando dentro de ellas la importancia estructural de elastina y tenascina $\mathrm{C}$.

Centrándonos en la matriz extracelular, encontramos el papel fundamental del tejido conjuntivo y el endotendon. El endontendon rodea a los haces de fibras de colágeno, subfasciculos, fascículos y haces de fascículos. Nos ayuda a canalizar los vasos sanguíneos, linfáticos, así como las estructuras nerviosas y constituye uno de los principales sistema de irrigación del tendón ${ }^{(4)}$.

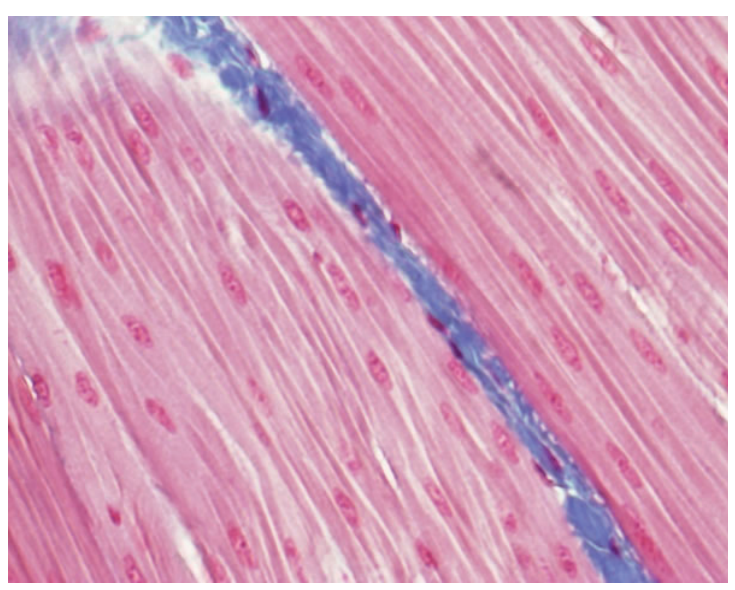

Figura 2. Colágeno estructurado.

Figura 1. Colágeno desestructurado. 
Encontramos también el peritendon como la siguiente estructura, rodea al tendón y podemos dividirlo en dos subcapas diferenciadas y de interés paratendon y epitendon.

\section{INERVACIÓN DEL TENDÓN}

Procede fundamentalmente de las estructuras musculares ${ }^{(5)}$, de las zonas cutáneas próximas, de las zonas peritendinosas vecinas y de los troncos nerviosos profundos. Sabemos que el tendón posee rica inervación con predominio de las aferencias, lo cual consideramos de importantísima significación en el desarrollo propioceptivo. Además encontramos una intima relación entre su capacidad empatica aferente y su papel en la transmisión y adecuación de fuerzas externas e internas.

Existen además diferentes terminaciones o receptores de interés, de los que poseemos un conocimiento amplio y que nombraremos brevemente a continuación:

1. Corpúsculos de Ruffini: Son receptores poco acomodables por lo que tienen un papel fundamental a la hora de señalar estadios continuados de deformación de piel o tejidos más profundos e informar sobre la presión

2. Corpúsculos de Pacini: Corpúsculos táctiles localizados en el estrato profundo, debido a su composición ovalada aportan una especial sensibilidad a las vibraciones con frecuencias entre 60 y 300 ciclos/seg.

3. Terminaciones Nerviosas Libres: Son receptoras del dolor e informan acerca de la presión, el tacto grueso, frío, calor y sustancias químicas

4. Órgano Tendinoso de Golgi: De una estructura compleja, cada órgano posee por una capsula fibrosa que rodea un pequeño haz de fibras intrafusales tendinosas, una o varias fibras nerviosas sensitivas mielinicas atraviesan la capsula, pierden su vaina de mielina, se ramifican y acaban en terminaciones sensitivas (fibras $\mathrm{Ib}$ ). Estos receptores tendinosos se hallan situados en serie con las fibras musculares. Su actividad es consciente y sus terminaciones encapsuladas se imbrican en la zona de inserción de las fibrillas musculares con el tendón, por lo que son sensibles a la distensión de los tendones por contracción del músculo correspondiente o de un músculo antagonista. Su función principal es regular el grado de tensión muscular y proteger al músculo de una situación de tensión excesiva. De marcado interés el reflejo miotatico inverso.

\section{VASCULARIZACIÓN DEL TENDÓN}

El suministro vascular esta comprometido en zonas donde el tendón esta sometido a fricción, torsión y/o compresión:

En estas zonas el colágeno tipo I, principal proteína del tendón es sustituido por colágeno tipo II, presente mayoritariamente en cartílago.

De esta forma algunos tendones presentan fisiológicamente ${ }^{(6)}$, zonas prácticamente avasculares, en el caso del tendón de Aquiles observamos una zona de estas características vasculares entre 2 y $5 \mathrm{~cm}$ sobre la inserción.

Tenemos que recordar que el tendón es una estructura relativamente avascular en comparación con otros tejidos, y que esta vascularización siendo variable, procede de 3 regiones principalmente:

- Unión Miotendinosa (vasos del perimisio).

- Superficie longitudinal del tendón (vasos del paratendon y mesotendon).

- Unión osteo-tendinosa (vasos del periostio).

\subsection{Unión Miotendinosa}

En esta zona la tensión generada desde fibras musculares se transmite desde las proteínas contráctiles hasta las fibras colágenas del tejido conjuntivo tendinoso.

Las fibras colágenas se insertan dentro de los profundos recesos formados entre las terminaciones en forma de dedo de las células musculares. Este tipo de pliegue de la membrana basal sirve para incrementar el área de contacto entre fibras colágenas y musculares de 10 a 20 veces mejorando su rendimiento mecánico.

La matriz extracelular a nivel tendinoso es rica en glucosaminoglicanos y proteoglicanos. A pesar de todo ello es una zona de asentamiento de lesiones, principalmente micro roturas tisulares de fibras por mecanismo indirecto. 


\subsection{Unión Osteotendinosa}

Dividiremos estructuralmente esta zona en 4 secciones: tendón, fibrocartílago, fibrocartílago mineralizado y hueso ${ }^{(7,8)}$.

1. Tendón. Esta formado por haces de fibras colágenas tipo I con alta densidad de tenoblastos entrelazados. Hacia la línea fibrocartilaginosa observamos un aumento moderado de matriz extracelular. Entre las fibrillas y los haces de fibrillas se observan grandes cantidades de glicosaminoglicanos, especialmente condroitin-sulfato.

2. Fibrocartílago. De forma gradual las fibras pierden su apariencia alargada y adquieren formas mas redondeadas, alcanzando mas similitud con condrocitos. Situadas en formato de parejas o hileras (también denominada sistema de distribución o referencia por pares) se encuentran rodeadas de un espacio lagunar de matriz extracelular.Aumentan en el citoplasma, el RER, aparato de Golgi, los lisosomas y las vacuolas lipídicas. Aparece una discreta envoltura rodeando de fibras de colágeno tipo II.

3. Unión Osteotendinosa. Las células son similares a los condrocitos de fibrocartílago aunque en este caso las encontramos rodeados de tejido mineralizado (corticomineralizado). La cantidad de sustancia fundamental rica en condroitina sulfato aumenta proporcionalmente. Las fibras colágenas alcanzan esta zona y el proceso de mineralización se realiza mediante depósitos de calcio en forma granular y cristales de hidroxiapatita situados entre las fibras colágenas.

4. Hueso. Las fibras colágenas de esta región no se distinguen de las de la zona de fibrocartílago mineralizado, este último segmento posee características muy similares al tejido óseo.

\section{COMPORTAMIENTO MECÁNICO DEL TENDÓN}

Estos dos axiomas que nombraremos a continuación nos ayudaran a conocer de una manera mas sencilla el comportamiento del tendón frente a las fuerzas que le rodean ${ }^{(9)}$.
Cuanto mayor sea la sección transversal de un tendón, mayores cargas podrá soportar antes de alcanzar el punto critico de rotura y cuanto mas largo sea un tendón mayor será la capacidad de elongación que posea antes de producirse la rotura (disminuye la rigidez $\sin$ alterarse la resistencia a la tracción)

Existen una serie de elementos intrínsecos que modifican las propiedades mecánicas del tendón como son la alineación u orientación de las fibras, la densidad de enlaces cruzados intra e intermoleculares (anteriormente nombrados), el numero de fibras y de fibrillas, la proporción de colágeno y elastina, el grado de hidratación y el grado de relajación de los componenentes contráctiles.

También existen elementos extrínsecos como son el entrenamiento físico o la inmovilización que modificara la capacidad de resistencia del tendón aumentándola y disminuyéndola respectivamente.

La actividad física sobre el tendón provoca diferentes modificaciones a saber:

Tejido tendinoso: aumenta la actividad de los tenocitos, aumenta la síntesis de colágeno y matriz de proteoglicanos en tendón, aumenta el número de fibras, grosor, el peso y la resistencia a la tracción

Unión miotendinosa: Aumento de la actividad fibroblastica, aumento de la secreción y del depósito de fibras de colágeno y sustancia fundamental, mejora la fatigabilidad y las propiedades viscoelasticas'.

Unión osteo-tendinosa encontramos un aumento de resistencia a las fuerzas de tensión en la unión osteoligamentosa.

La inmovilización sobre el tendón provoca también diferentes modificaciones, a saber:

Tejido tendinoso: Disminución de elasticidad y peso toral del tendón, existe un adelgazamiento de fibras colágenas y desorientación, disminución importante de la red capilar así como el agua de la matriz extracelular y degeneración hipoxica de los tenocitos.

Unión miotendinosa: En la primera semana disminuye el área de contacto de las células musculares y las fibras de colágeno. En la tercera semana esta reducción llega al 50\%, con marcada perdida de colágeno tipo I, aumento de colágeno tipo III, disminución de la tenascina C.Mas adelante encontramos un acumulo 
de tejido conectivo denso y proliferación de fibroblastos, con aumento de colágeno tipo III y disminución de glicosaminoglicanos.

Unión osteotendinosa: Disminución de la elasticidad y resistencia al arrancamiento en la inserción osteoligamentosa y alteración del proceso de remodelación óseo en dicha unión.

\section{ACTUALIZACIÓN EN TENDINOPATIAS}

Desde el 2000 los estudios de Alfredson y Lorentzon concluyeron que los términos: tendinitis, tendinitis, cambios por degeneración, tendinopatia crónica y ruptura parcial (excluyendo aquellos casos de inicio súbito)implican cambios en el tendón que se pueden definir como tendinosis ${ }^{(10)}$.

Las características principales de la tendinosis son la degeneración del colágeno con desorientación del colágeno y separación fibrilar, existe además aumento de la sustancia fundamental y ausencia de marcadores inflamatorios (PG2). Se aprecia una degeneración cierta del tejido colágeno, caracterizada por perdida de la alineación y densidad fibrilar, aumento de la sustancia fundamental mucoide (proteoglicanos) y ausencia de células inflamatorias ${ }^{(11)}$.

Bajo microscopia de alta resolución, se observa separación de fibras colágenas con disminución de diámetro y densidad.

Aparecen microroturas en las fibras de colágeno, siendo estas zonas rodeadas posteriormente por eritrocitos, fibrina y depósitos de fibronectina propias de la neoangiogenesis.
En los estudios clásicos de biopsias en tendones con dolor crónico no hay células inflamatorias.

La microdialisis confirma la ausencia de inflamación. Histológicamente no hay células inflamatorias. Cambia la estructura y se modifica la forma y la disposición de las fibras de colágeno. En el interior de las fibras colágenas se observan variaciones en la disposición ondulada (crimp) con mayor ondulación (en contraposición a la compacta y paralela apariencia normal) y disminución del numero de fibras ${ }^{(12)}$. Aparecen espacios vasculares con o sin neovascularizacion y/o calcificación focalizadas.

En la tendinosis existe gran variedad de la densidad celular. En algunas zonas del tendón, los tenocitos son anormalmente abundantes y presentando un núcleo redondeado, con un evidente ultraestructural aumento en la producción de proteoglicanos y proteínas, lo que le confiere apariencia condroide.

En contraste a estos hallazgos, en otras zonas se observa una concentración de tenocitos menor de lo normal, siendo estos más pequeños y con un núcleo picnotico.

Pocas veces aparecen infiltrados de linfocitos y macrófagos, los cuales forman parte del proceso de reparación.

Un rasgo característico de las tendinosis es la proliferación de capilares y arteriolas, con hiperplasia endotelial y trombosis microvascular coherentes a un proceso de neoangiogenesis y que consideramos un primer paso en el fracaso de reparación y que tiende a favorecer la tendinosas.

\section{BIBLIOGRAFIA}

1. Ingber, D. Mannix, R. Mechanical Behaviour in living cells consistent with tensegrity model. Proceedings of the National Academy of Sciences of the United States of America, 2001;(14):7765-7770.

2. Zipora, Y. Seger, R. Fibroblast Growth factor promotes recruitment of skeletal muscle satellite cells in young and old rats. The Journal of histochemistrus and cytochemistry, 1999;47(1): 23-42.

3. Ingber, D. Whitesides, G. Engineering Cell Shape and Function. Science, New Series, 1994;(29): 696698.

4. Zammit, P. Golding, J. Muscle satellite cells adopt divergent fates: a mechanism for self-renewal?. The Journal of cell biology, 2004;166(3): 347-357.

5. Anderson, J. the satellite cell as a companion in skeletal muscle plasticity: currency, conveyance, clue connector and colander. The Journal of experimental biology, 2006; 299: 2276-2292.

6. Ingberg, D. Zhou, J. Global cytoeskeletal control of mechanotransduccion in kidney epithelial cells. Experimental Cell research, 2004; 301: 23-30. 
7. Crameri, M. Aaagard, P. Myofibre damage in human skeletal muscle: effects of electrical stimulation versus voluntary contraction. Journal Physiology, 2007; 1: 365-380.

8. Ingberg, D. Butler, P. Mechanotransduction across the cell surface and trough the cytoskeleton. Science, New Series. 1993; 260 (3): 1124-1127.

9. Benjamin, M. Toumi, H. Where tendons and ligaments meet bone: attachment sites in relation to exercise and/or mechanical load. Journal Anatomy, 2006; 208 (1): 471-490.

10. Hoksrud A, Ohberg L, Alfredson H, Bahr R. Color Doppler ultrasound findings in patellar tendinopathy (jumper's knee). American Journal Sports Medicine. 2008;36(9):1813-20.

11. Chan KM, Fu SC. Anti-inflammatory management for tendon injuries - friends or foes?. Sports Medicine Arthroscopy Rehabilitation Therapy Technology. 2009; 13;1(1):23.

12. Pearce CJ, Ismail M, Calder JD. Is Apoptosis the Cause of Noninsertional Achilles Tendinopathy? American Journal Sports Medicine. 2009; 9: 1(2):36. 